\title{
1 Impact of the Green Light Program on haze pollution in 2 the North China Plain, China
}

3 Xin Long ${ }^{1,3,7}$, Xuexi Tie $^{1,2,3,4,5^{*}}$, Jiamao Zhou ${ }^{3}$, Wenting Dai ${ }^{3}$, Xueke Li ${ }^{6}$, Tian 4 Feng $^{1}$, Guohui $\mathrm{Li}^{1,3}$, Junji Cao ${ }^{1,3}$, and Zhisheng $\mathrm{An}^{1}$

$5{ }^{1}$ State Key Laboratory of Loess and Quaternary Geology, SKLLQG, Institute of Earth

6 Environment, Chinese Academy of Sciences, Xi' an 710061, China

$7 \quad{ }^{2}$ Center for Excellence in Urban Atmospheric Environment, Institute of Urban Environment,

8 Chinese Academy of Sciences, Xiamen 361021, China

$9 \quad{ }^{3}$ Key Laboratory of Aerosol Chemistry and Physics, Institute of Earth Environment, Chinese

10 Academy of Sciences, Xi' an 710061, China

$11{ }^{4}$ Shanghai Key Laboratory of Meteorology and Health, Shanghai, 200030, China

$12{ }^{5}$ National Center for Atmospheric Research, Boulder, CO 80303, USA

$13{ }^{6}$ Department of Geography, University of Connecticut, Storrs, Mansfield, CT 06269, USA

$14{ }^{7}$ School of Environment Science and Engineering, Southern University of Science and 15 Technology, Shenzhen 518055, China

16

17 Correspondence to: Xuexi Tie (email: xxtie@ucar.edu) 


\section{Supplementary Figure Captions}

Figure S1. (a) The spatial distribution of VIIRS NTL radiance in 2015 and (b) the provincial dynamics of the lighting electricity consumption.

Figure S2. The species variations of $\mathrm{PM}_{2.5} 、 \mathrm{NO}_{2}$, and $\mathrm{SO}_{2}$ within the areas with high $\mathrm{PM}_{2.5}$ changes induced by the GLP(see red-square in Fig.8).

Figure S3. The lower (left panels) and upper (right panels) episode-averaged variations of $\mathrm{O}_{3}$ $\left(\mu \mathrm{g} \mathrm{m}^{-3}\right)$ induced by GLP, including. The results refer to the spatial variations between the REF case and the SEN-GLPs case (REF - SNE-GLPs). 
Fig. S1
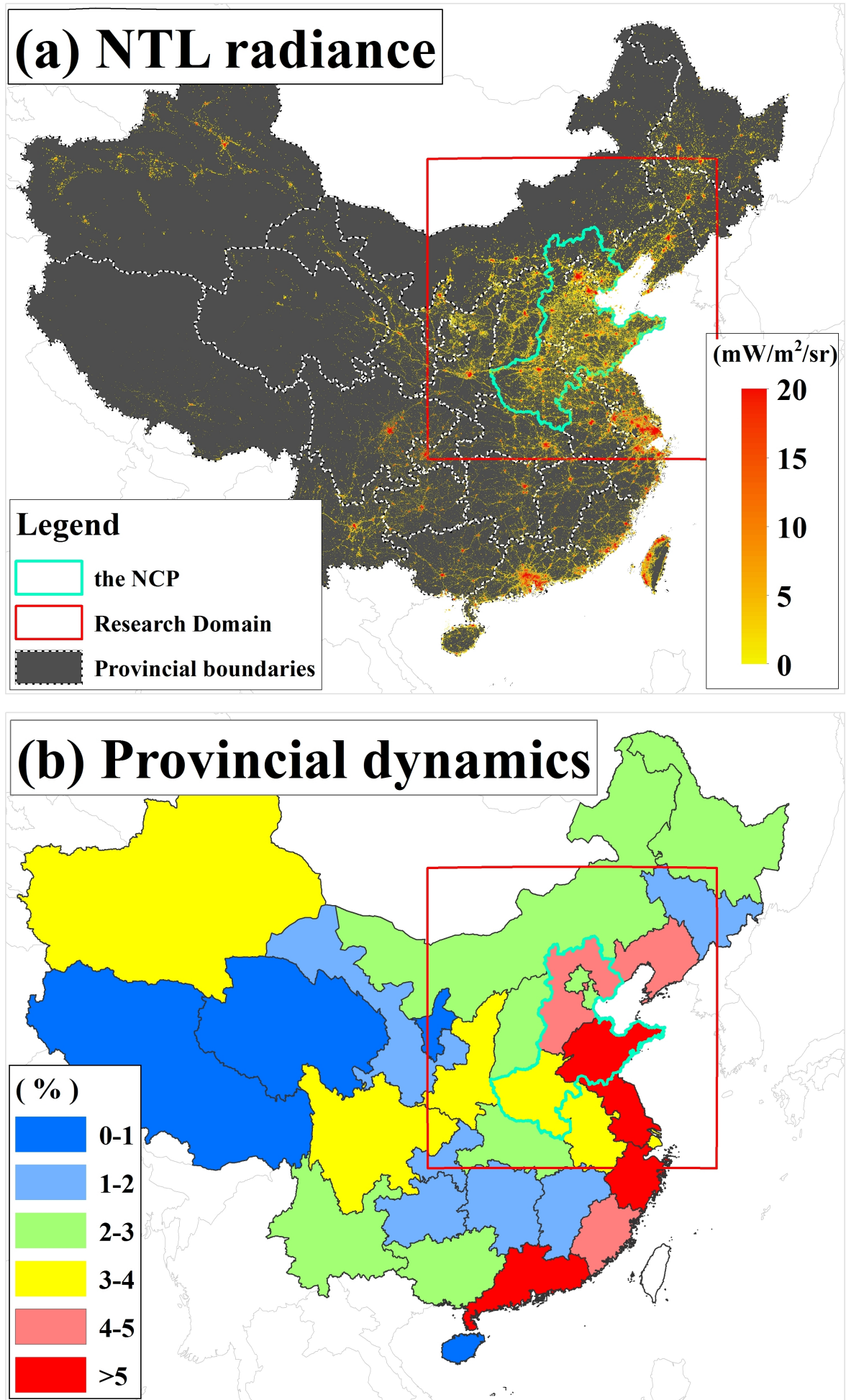

Figure S1. (a) The spatial distribution of VIIRS NTL radiance in 2015 and (b) the provincial dynamics of the lighting electricity consumption. 
Fig. S2
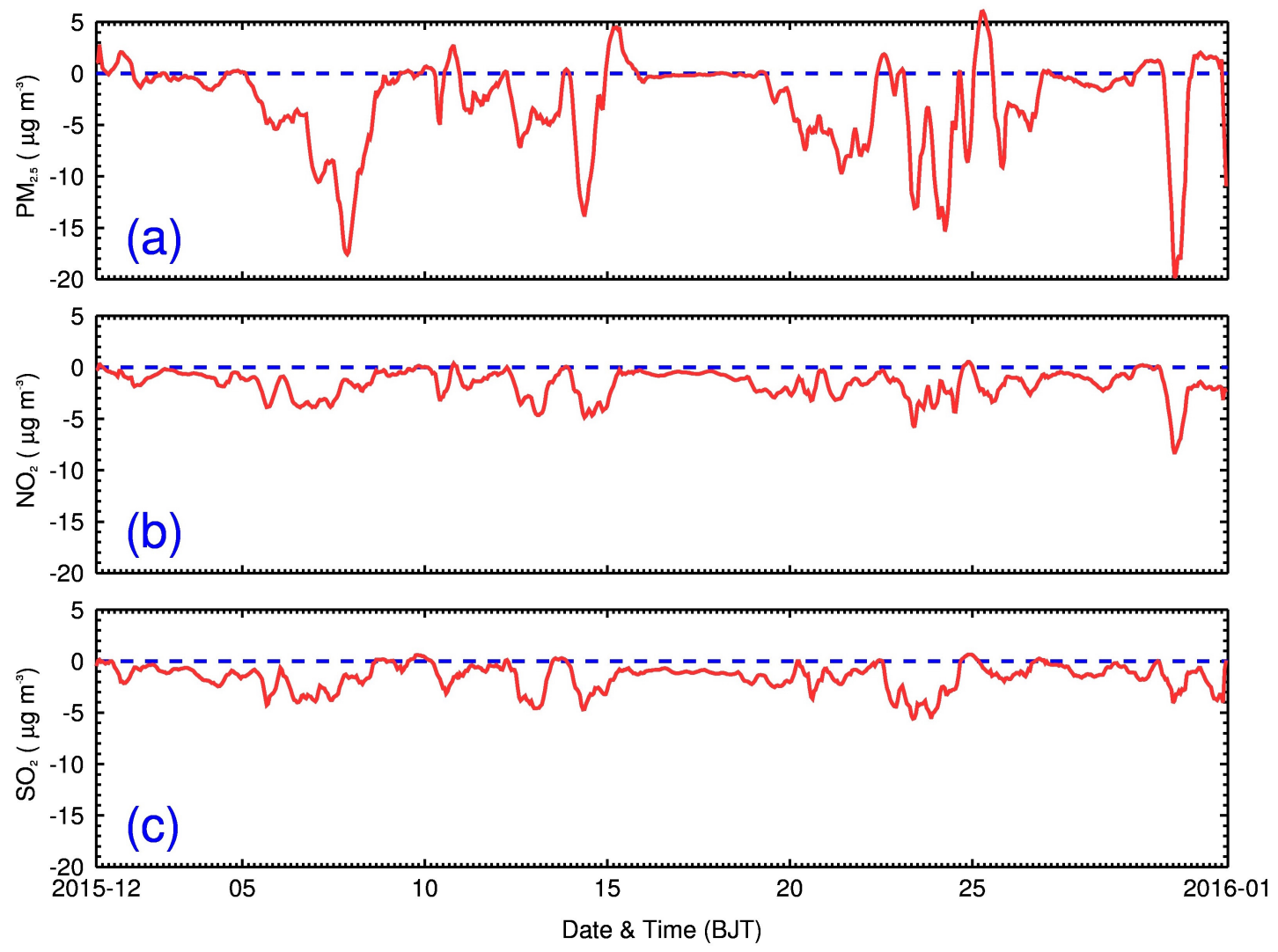

Figure S2. The species variations of $\mathrm{PM}_{2.5}, \mathrm{NO}_{2}$, and $\mathrm{SO}_{2}$ within the areas with high $\mathrm{PM}_{2.5}$ changes induced by the GLP(see red-square in Fig.8). 
Fig. S3

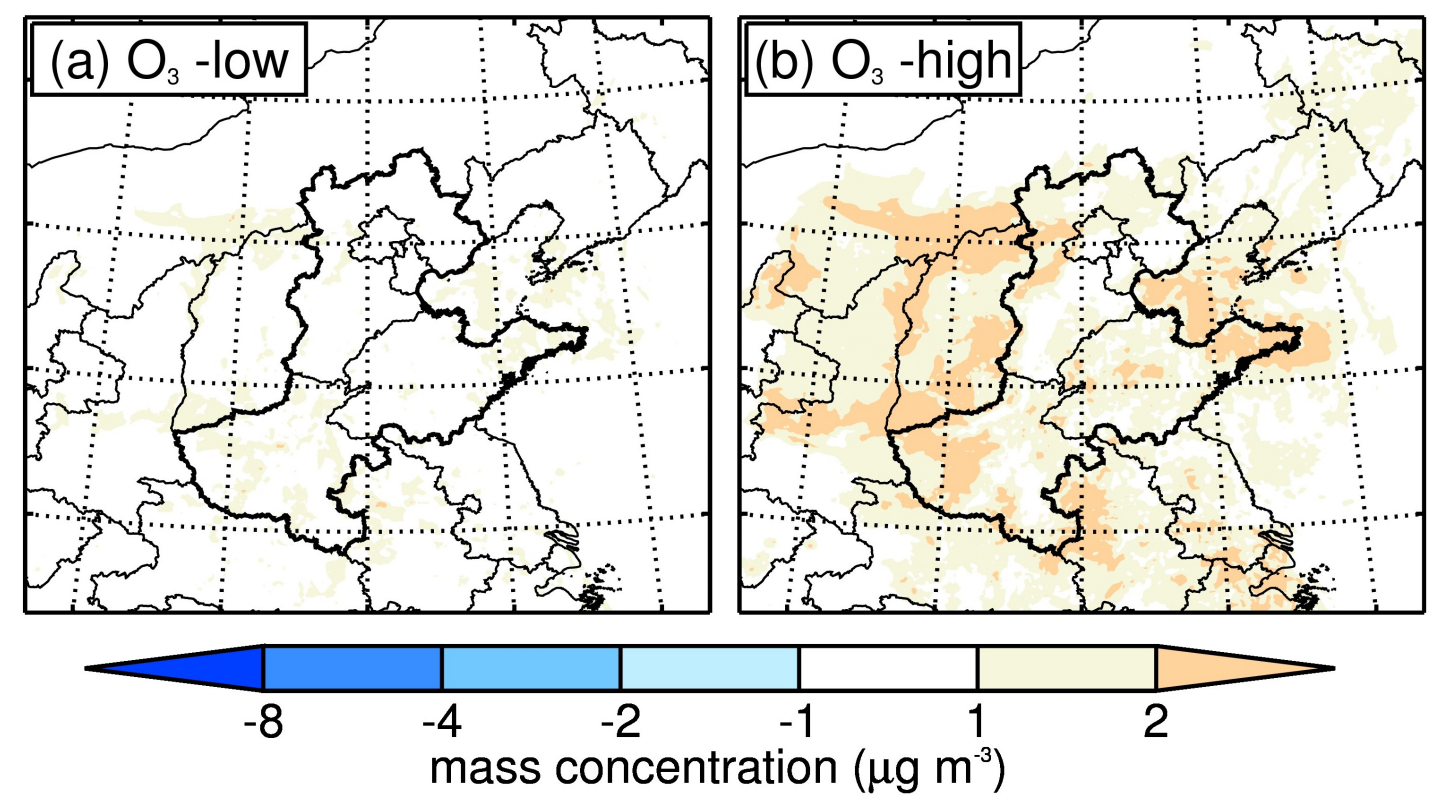

Figure S3. The lower (left panels) and upper (right panels) episode-averaged variations of $\mathrm{O}_{3}$ $\left(\mu \mathrm{g} \mathrm{m}^{-3}\right)$ induced by GLP, including. The results refer to the spatial variations between the REF case and the SEN-GLPs case (REF - SNE-GLPs). 